Association for Information Systems

AIS Electronic Library (AISeL)

\title{
Don't Want It Anymore? Resilience as a Shield Against Social Media-Induced Overloads
}

\author{
Alena Bermes \\ Heinrich Heine University Düsseldorf, Chair of Marketing, Düsseldorf, Germany \\ Clara-Lea Gromek \\ Heinrich Heine University Düsseldorf, Chair of Marketing, Düsseldorf, Germany
}

Follow this and additional works at: https://aisel.aisnet.org/wi2021

Bermes, Alena and Gromek, Clara-Lea, "Don't Want It Anymore? Resilience as a Shield Against Social Media-Induced Overloads" (2021). Wirtschaftsinformatik 2021 Proceedings. 1.

https://aisel.aisnet.org/wi2021/MSocialMedia13/Track13/1

This material is brought to you by the Wirtschaftsinformatik at AIS Electronic Library (AISeL). It has been accepted for inclusion in Wirtschaftsinformatik 2021 Proceedings by an authorized administrator of AIS Electronic Library (AISeL). For more information, please contact elibrary@aisnet.org. 


\title{
Don't Want It Anymore? Resilience as a Shield Against Social Media-Induced Overloads
}

\author{
Alena Bermes ${ }^{1}$ and Clara-Lea Gromek ${ }^{1}$ \\ ${ }^{1}$ Heinrich Heine University Düsseldorf, Chair of Marketing, Düsseldorf, Germany \\ \{alena.bermes, clara-lea.gromek\}@uni-duesseldorf.de
}

\begin{abstract}
Social media have become part of millions of users' everyday life, leading to the proliferation of the daily stressors associated with them, particularly social media-induced overloads. Therefore, understanding the individual characteristics that enable users to resist such stress factors and ultimately buffer negative follow-up effects, such as exhaustion and discontinuance behavior, is important for researchers and practitioners. Grounded in psychological resilience theory, we examine if a user's resilience (one's ability to bounce back) has the power to mitigate the effects of this critical chain of influence by inhibiting the stressors. Structural equation modelling on survey data from 194 social network users confirms that resilience decreases perceived information and social overload. We also find that self-efficacy is a protective factor leading to resilience. Therein, this short paper raises awareness on resilience's function as a shield against the adverse effects of social media and provides a comprehensive outlook for future research.
\end{abstract}

Keywords: SNS resilience, protective (resilience) factors, social media-induced overloads, technostress

\section{Introduction}

The concept of resilience is omnipresent. While it holds different meanings depending on the context [1], researchers and practitioners, regardless of the discipline, agree that it serves as shield for individuals, groups, and society [2]. Grounded in psychological research, specifically, resilience refers to an individual's ability to bounce back in the face of adversity and stress [3]. Since a high number of individuals are affected by technology-induced stress every day $[4,5]$ and since technostress is reported to be a major concern due to lowered end-user productivity [6], satisfaction [7], and well-being [8], Klesel et al. [9] introduced the concept of resilience to Information Systems (IS) research, conceptualizing it as one's ability to counteract technology-related stressors. Therein, the theoretical relevance of the concept of resilience for IS research has been acknowledged, but crucial questions remain to be addressed. The mitigating effect of resilience on specific technology-related stressors has not yet been proven empirically, and the question remains as to how resilience in the IS domain can be developed.

We seek to address this gap by examining resilience in the face of social mediainduced stressors, particularly social overload (SO) and information overload (IO). The 
context is relevant and timely since the widespread use of social network sites (SNS), having become one of the most popular Internet services globally [10], is known to induce perpetual obsessions and create pressure for users to keep up to date and react to each other's postings [11]. Moreover, both types of overloads are particularly prevalent in the time of COVID-19 [12], therefore augmenting the call to understand how they may be mitigated [11]. Importantly, earlier research demonstrates that overloads on SNS do not only place the business models of SNS providers at risk (by leading users to discontinue their social network use) [13], but also significantly decrease users' well-being [14]. Hence, in this short paper, we specifically shed light on the concept of SNS resilience by addressing the following research questions:

RQ1. Does SNS resilience have the power to inhibit social media-induced overloads?

RQ2. If so, how can SNS resilience among social media users be build?

\section{Conceptual Development}

\subsection{Resilience as a Means to Combat Stressors}

The concept of resilience is derived from the Latin word 'resilire', meaning to jump back or rebound [3]. It is best exemplified by the metaphor of metals bending (not breaking) when stressed [15] and marks an aspect of focus for different communities of practice (for selected reviews see [16] for psychological resilience and [2] for social (ecological) resilience). This work builds on previous psychological resilience research that mostly explores the concept at the individual level [17]. At the individual level, resilience not only describes one's ability to withstand stress, but also emerge from that situation better equipped for future adversities [16]. The scant work done in the area of IS and user behavior is striking, as psychologists have long demonstrated that resilient individuals are able to endure adversities (e.g., trauma) better than non- or less resilient individuals [1]. Moreover, IS-adjacent scholars (i.e., in management and marketing) have started to demonstrate that resilience can serve as a shield in work-related [17] or consumption-related stress processes [18], for example, in terms of job (dis)satisfaction [19], turnover intentions [20], or consumer experiences of austerity [21].

Despite the construct of resilience having been conceptualized in a number of ways, most modern scholars agree that resilience is not a trait that one must be born with to have; rather, it can partly be learned [22]. Moreover, the notion of 'adversity' is inherent in most definitions [16] and today it is of no question that adversity is associated with not only major disasters (e.g., death of a spouse), but also modest disruptions embedded in everyday lives [23]. In our study, acceding to the request that resilience researchers outline their notion of adversity [24], we specifically examine users' SNS resilience as the ability to bounce back in the face of social media-induced stressors. By adhering to the understanding of resilience as a capacity [17], we acknowledge that individuals can be trained to become resilient [25], which makes the construct particularly valuable.

Overload perceptions - the individual's evaluation that the number of demands from the environment exceeds one's ability to deal with [13] - represent common socialmedia induced stressors that are present in social media. Particularly $I O$ and $S O$ are 
known to be major technology-induced stressors that users experience on a daily basis. While the former refers to information volumes exceeding a user's processing capacity in a certain unit of time [13], the latter concerns an overwhelming number of requests from online contacts that demand a user's attention [26]. As such, both constitute an imbalance between a user's perceived demands and coping abilities, leading to strain and, ultimately, negative outcomes [4].

Drawing on psychological resilience theory [27] we assume that users' resilience has the power to mitigate such overload perception, because it entails the ability to bounce back. As such, users with high resilience should appraise stressors as less harmful and experience them less strongly, because they intrinsically possess the ability to resist stress factors and perceive them as less troublesome [16]. Prior empirical research also suggests that resilience inhibits stressors similar in nature to IO and SO. For example, Richards et al. [28] revealed that resilience decreases overloads in the context of work stress, i.e., role overloads. Accordingly, we posit that SNS resilience decreases perceived IO (H1) and SO (H2).

\subsection{Protective Factors Leading to Resilience}

Resources within individuals and their environment, referred to as protective or resilience factors, promote an individual's ability to have resilience [27]. As such, external or internal protective factors are an integral part of resilience theory. Psychological research shows that protective factors often function in cumulative ways [29] and exist across three levels: individual, social, and community/society [1]. Social support and self-efficacy are particularly well-documented factors for resilience within an individual and their immediate social environment [30, 31].

While psychological resilience research describes social support as support received by an individual through social ties to others [32], social support in the digital era has specifically been defined as the extent to which SNS users are taken care of by their online friends [33]. Such support from one's immediate environment should operate as a protective factor leading to resilience, because it reinforces the user's ability to positively adapt by providing a generally positive, caring context [34]. To be precise, already, the very earliest resilience studies have found that children who were born into adverse conditions (e.g., into families troubled by chronic discord) profited from the external support of surrogate parents or the community (e.g., caring neighbors) and could develop into resilient individuals later, although their origin would have suggested otherwise [35]. Hence, drawing on psychological resilience theory and prior empirical findings, we hypothesize that social support increases SNS resilience (H3).

Self-efficacy in relation to SNS usage (i.e., SNS self-efficacy) might best be described as an individual's efficacy in addressing specific SNS-related stressors. This definition is derived from Marakas et al.'s [36] broader concept of computer selfefficacy. According to psychological resilience research, self-efficacy should lead to resilience because it improves the user's adaptational system [22] and increases their motivation and perseverance [37]. In particular, there is vast empirical evidence showing that self-efficacy is one of the most important resilience (protective) factors [38] and increases one's resilience in contexts such as academia [37], entrepreneurship 
[39], or military combat [31]. Based on psychological resilience theory and previous empirical research, we therefore hypothesize that (SNS) self-efficacy increases SNS resilience $(\mathrm{H} 4)$.

\section{$3 \quad$ Empirical Study}

To examine our hypotheses, we conducted an online survey via a consumer panel in Germany in July 2020. A total of 232 participants completed the survey. We only considered datasets from participants currently using SNS and showing careful response patterns [40], resulting in 194 valid responses (female $=70.1 \%, \mathrm{M}_{\text {age }}=29.66$, $\left.\mathrm{SD}_{\mathrm{age}}=10.85\right)$. All respondents used more than one SNS and the majority of the respondents $(87.6 \%)$ reported that SNS were an integral part of their daily lives.

For measurement purposes, we used well-established and reliable multi-item scales from prior academic literature, ranging from "strongly disagree" (1) to "strongly agree" (7). SNS resilience was adapted from Smith et al. [3] and Klesel et al. [9]. We included the specific context into the scale as per Klesel et al. [9], asking the respondents to imagine situations where SNS use caused stress, followed by the items of the renowned Brief Resilience Scale [3, 41], e.g., “... I tend to bounce back quickly”. IO and SO were assessed based on Zhang et al. [42] and Maier et al. [26]. Items included "I find that I am overwhelmed by the amount of information I have to process on a daily basis on SNS" (IO) and "I pay too much attention to posts of my friends on SNS" (SO). Social support was measured as per Lo [33] (e.g., "I get a lot of social support from my friends on SNS") and SNS self-efficacy was adapted from Marakas et al. [36] by replacing references to the computer with SNS (e.g., "I have the ability to describe how SNS work"). Where available, validated German translations were used (e.g., [43]).

To analyze the data, we employed the partial least squares (PLS) method. Specifically, SmartPLS3 [44] was used following the two-stage approach [45] to estimate both the measurement model and structural model. First, to validate the measurement model, we assessed the reliability, convergent validity, and discriminant validity of the constructs. Cronbach's alpha values ranging from 0.80 to 0.94 [46], composite reliabilities ranging from 0.87 to 0.96 [47], average variances extracted (AVE) ranging from 0.63 to 0.81 [48], and standardized factor loadings ranging from 0.70 to 0.93 [49] exceeded the recommended thresholds, signifying sufficient reliability and convergent validity. The square root of the AVE for each construct exceeded the interconstruct correlations, indicating discriminant validity [48]. Furthermore, we evaluated the common method bias (CMB) by employing the marker variable approach [50] with the theoretically unrelated marker variable 'attitude toward the color blue'. The results showed that CMB was not a concern. Second, we estimated the PLS results of the structural model. The results revealed that resilience decreased both IO $(\beta=$ $-0.522, t=10.413, p<0.001)$ and SO $(\beta=-0.377, t=5.550, p<0.001)$, supporting $\mathrm{H} 1$ and H2. Moreover, self-efficacy was found to increase SNS resilience $(\beta=0.312, t$ $=5.391, p<0.001)$, confirming H4. However, social support was found to decrease SNS resilience $(\beta=-0.261, t=4.484, p<0.001)$, rejecting $\mathrm{H} 3$ and the notion that social 
support is a protective factor for SNS resilience. The model explained $15.2 \%$ of the variance of SNS resilience and $27.3 \%$ and $14.2 \%$ of the variances of IO and SO.

\section{Discussion and Outlook}

This study was a first step taken to examine whether SNS resilience inhibits stressors and to determine how it can be built. With our efforts, we heed the call to explore mitigating mechanisms within the SNS-induced stress process [11] and to establish the construct of resilience in the IS realm [9]. Grounded in psychological resilience theory, our study confirms the mitigating power of SNS resilience against IO and SO. This initial proof of resilience's function as a shield may explain why some users can handle technostress better than others. Future research could also examine resilience against other 'dark sides' of SNS, e.g., addictive use [51], or other IS-related adversities [52].

For the question of which factors lead to SNS resilience, our study shows mixed results. While self-efficacy increases SNS resilience, social support decreases it. The latter is striking as psychological theory clearly proposes that external support leads to resilience [31]. Yet, selected research also shows that the required type of support may change over time as a function of personal development and environmental interaction [53]. Moreover, studies on SNS discontinuance show that social support on SNS can transform into social overload due to reciprocal dynamics [54]. This may explain social support's inhibiting effect as it may be perceived as a burden in itself. Future studies should investigate which theoretically founded factors truly enhance SNS resilience.

Our results highlight that SNS resilience is a noteworthy concept that researchers and practitioners alike should consider, as it can mitigate the stressors leading to strain and negative outcomes [13]. SNS providers can profit from our findings by integrating SNS resilience into their customer relationship management process [55]. For example, by segmenting users based on their level of resilience, providers can address each segment specifically. Moreover, intervention strategies to foster resilience are highly recommended. These programs often rely on strengthening the protective factors [25]. To this end, computerized trainings [56] or mobile games [57] may be valuable tools.

As any, our study has limitations, each equally leaving room for future research. First, as this is a cross-sectional study, we will continue with a longitudinal design to examine potential changes in SNS resilience over time [34] and understand resilience's exact role as an inhibitor in the causal stress process related to SNS usage. Second, this study was based on a gender imbalanced sample. Future studies will be more weighted and also perform group analyses for gender and age (both known to affect technostress perception $[13,58])$. Third, in subsequent studies, we will also examine the context dependence of resilience [22] and test our conceptual model within the different SNS, given that different types of networks may fulfill different purposes for the user [26].

\section{References}

1. Windle, G.: What is resilience? A review and concept analysis. Reviews in Clinical Gerontology. 21, 152-169 (2011) 
2. Keck, M., Sakdapolrak, P.: What Is Social Resilience? Lessons Learned and Ways Forward. Erdkunde. 67, 5-19 (2013)

3. Smith, B.W., Dalen, J., Wiggins, K., Tooley, E., Christopher, P., Bernard, P.: The Brief Resilience Scale: Assessing the Ability to Bounce Back. International Journal of Behavioral Medicine. 15, 194-200 (2008)

4. Ayyagari, R., Grover, V., Purvis, R.: Technostress: Technological Antecedents and Implications. MIS Quarterly. 35, 831-858 (2011)

5. Maier, C., Laumer, S., Weinert, C., Weitzel, T. (2015). The effects of technostress and switching stress on discontinued use of social networking services: a study of Facebook use. Information Systems Journal. 25, 275-308 (2015)

6. Tarafdar, M., Tu, Q., Ragu-Nathan, B.S., Ragu-Nathan, T.S.: The Impact of Technostress on Role Stress and Productivity. Journal of Management Information Systems. 24, 301-328 (2007)

7. Tarafdar, M., Tu, Q., Ragu-Nathan, T.S.: Impact of Technostress on End-User Satisfaction and Performance. Journal of Management Information Systems. 27, 303-334 (2011)

8. Tarafdar, M., D'Arcy, J., Turel, O., Gupta, A.: The Dark Side of Information Technology. MIT Sloan Management Review. 56, 60-70 (2015)

9. Klesel, M., Narjes, N., Niehaves, B.: Conceptualizing IT Resilience: An Explorative Approach. Multikonferenz Wirtschaftsinformatik. 1008-1019 (2018)

10. Global Web Index, http://www.globalwebindex.com/reports/social (Accessed: 23.11.2020)

11. Lee, A.R., Son, S.-M., Kim, K.K.: Information and communication technology overload and social networking service fatigue: A stress perspective. Computers in Human Behavior. 55, 51-61 (2016)

12. Bermes, A.: Stop It! Consumer Resilience as a Buffer Against Daily Stressors Accompanying COVID-19. In: Proceedings of the 23rd International Conference on Multidisciplinary Studies: "Resilience for Survival". Cambridge, UK (2020)

13. Zhang, S., Zhao, L. Lu, Y., Yang, J.: Do you get tired of socializing? An empirical explanation of discontinuous usage behaviour in social network services. Information \& Management. 53, 904-914 (2016)

14. Lee, S.B., Lee, S.C., Suh, Y.H.: Technostress from mobile communication and its impact on quality of life and productivity. Total Quality Management \& Business Excellence. 27, 775-790 (2016)

15. Lazarus, R.S.: From Psychological Stress to Emotions: A History of Changing Outlooks. Annual Review of Psychology. 44, 1-21 (1993)

16. Fletcher, D., Sarkar, M.: Psychological Resilience: A Review and Critique of Definitions, Concepts, and Theory. European Psychologist. 18, 12-23 (2013)

17. Kossek, E.E., Perrigino, M.B.: Resilience: A Review Using a Grounded Integrated Occupational Approach. The Academy of Management Annals. 10, 729-797 (2016)

18. Bhattacharyya, A., Belk, R.W.: Consumer resilience and subservience in technology consumption by the poor. Consumption Markets \& Culture. 22, 489-507 (2019)

19. Youssef, C.M., Luthans, F.: Positive Organizational Behavior in the Workplace: The Impact of Hope, Optimism, and Resilience. Journal of Management. 33, 774-800 (2007)

20. Bande, B., Fernández-Ferrín, P., Varela, J.A., Jaramillo, F.: Emotions and salesperson propensity to leave: The effects of emotional intelligence and resilience. Industrial Marketing Management. 44, 142-153 (2015)

21. Szmigin, I.T., O'Loughlin, D.M., McEachern, M.G., Karantinou, K.., Barbosa, B., Lamprinakos, G., Fernández-Moya, E.M.: Keep calm and carry on: European consumers and the development of persistent resilience in the face of austerity. European Journal of Marketing. 54, 1883-1907 (2020) 
22. Masten, A.S.: Ordinary Magic: Resilience Processes in Development. American Psychologist. 56, 227-238 (2001)

23. Davis, M.C., Linda L., Lemery-Chalfant, K.: Resilience in Common Life: Introduction to the Special Issue. Journal of Personality. 77, 1637-1644 (2009)

24. Luthar, S.S., Cicchetti, D., Becker, B.: The Construct of Resilience: A Critical Evaluation and Guidelines for Future Work. Child Development. 71, 543-562 (2000)

25. Macedo, T., Wilheim, L., Gonçalves, R., Coutinho, E.S.F., Vilete, L., Figueira, I., Ventura, P.: Building resilience for future adversity: a systematic review of interventions in nonclinical samples of adults. BMC Psychiatry. 14, 227 (2014)

26. Maier, C., Laumer, S., Eckhardt, A., Weitzel, T.: Giving too much social support: social overload on social networking sites. European Journal of Information Systems. 24, 447-464 (2015)

27. Richardson, G.E.: The Metatheory of Resilience and Resiliency. Journal of Clinical Psychology. 58, 307-321 (2002)

28. Richards, K.A.R., Levesque-Bristol, C., Templin, T.J., Graber, K.C.: The impact of resilience on role stressors and burnout in elementary and secondary teachers. Social Psychology of Education 19, 511-536 (2016)

29. Vanhove, A.J., Herian, M.N., Perez, A.L.U., Harms, P.D., Lester, P.B.: Can resilience be developed at work? A meta-analytic review of resilience-building programme effectiveness. Journal of Occupational and Organizational Psychology. 89, 278-307 (2016)

30. Lee, J.H., Nam, S.K., Kim, A.R., Kim, B., Lee, M.Y., Lee, S.M.: Resilience: A MetaAnalytic Approach. Journal of Counseling and Development. 91, 269-279 (2013)

31. Southwick, S.M., Charney, D.S.: The Science of Resilience: Implications for the Prevention and Treatment of Depression. Science. 338, 79-82 (2012)

32. Ozbay, F., Johnson, D.C., Dimoulas, E., Morgan III, C.A., Charney, D., Southwick, S.M.: Social Support and Resilience to Stress: From Neurobiology to Clinical Practice. Psychiatry (Edgmont), 4, 35-40 (2007)

33. Lo, J.: Exploring the Buffer Effect of Receiving Social Support on Lonely and Emotionally Unstable Social Networking Users. Computers in Human Behavior. 90, 103-116 (2019)

34. Rutter, M.D.: Psychosocial Resilience and Protective Mechanisms. American Journal of Orthopsychiatry. 57, 316-331 (1987)

35. Werner, E.: Resilience and recovery: Findings from the Kauai longitudinal study. Research, Policy, and Practice in Children's Mental Health. 19, 11-14 (2005)

36. Marakas, G.M., Johnson, R.D., Clay, P.F.: The Evolving Nature of the Computer SelfEfficacy Construct: An Empirical Investigation of Measurement Construction, Validity, Reliability and Stability Over Time. Journal of the Association for Information Systems. 8, $16-46(2007)$

37. Cassidy, S.: Resilience Building in Students: The Role of Academic Self-Efficacy. Frontiers in Psychology. 6, 1781 (2015)

38. Masten, A.S., Cutuli, J.J., Herbers, J.E., Reed, M.-G.J.: Resilience in Development. In Lopez, S.J, Snyder, C.R. (eds.) Oxford Handbook of Positive Psychology, pp. 117-131. Oxford University Press, Oxford (2009)

39. Bullough, A., Renko, M.: Entrepreneurial resilience during challenging times. Business Horizons. 56, 343-350 (2013)

40. Meade, A.W., Craig, S.B.: Identifying careless responses in survey data. Psychological Methods. 17, 437-455 (2012)

41. Windle, G., Bennett, K.M., Noyes, J.: A methodological review of resilience measurement scales. Health and Quality of Life Outcomes. 9, 8 (2011) 
42. Zhang, S., Zhao, L., Lu, Y., Yang, J.: Get Tired of Socializing as Social Animal? An Empirical Explanation on Discontinuous Usage Behavior in Social Network Services. In: Proceedings of the 19th Pacific Asia Conference on Information Systems. Singapore (2015)

43. Chmitorz, A., Wenzel, M., Stieglitz R.-D., Kunzler, A., Bagusat, C., Helmreich, I., Gerlicher, A., Kampa, M., Kubiak, T., Kalisch, R., Lieb, K., Tüscher, O.: Population-based validation of a German version of the Brief Resilience Scale. PLoS ONE. 13, e0192761 (2018)

44. Ringle, C.M., Wende, S., Becker, J.-M.: SmartPLS 3. SmartPLS GmbH, Boenningstedt (2013)

45. Hair, J.F., Black, W.C., Babin, B.J., Anderson, R.E.: Multivariate Data Analysis: A Global Perspective. Prentice-Hall, Englewood Cliffs (2010)

46. Nunally, J.C., Bernstein, I.H.: Psychometric Theory. McGRaw Hill, New York (1978)

47. Bagozzi, R.P., Yi, Y.: On the Evaluation of Structural Equation Models. Journal of the Academy of Marketing Science. 16, 74-94 (1998)

48. Fornell, C., Larcker, D.F.: Evaluating Structural Equation Models with Unobservable Variables and Measurement Error. Journal of Marketing Research. 18, 39-50 (1981)

49. Barclay, D., Higgins, C., Thompson, R.: The Partial Least Squares (PLS) Approach to Causal Modeling: Personal Computer Use as an Illustration. Technology Studies. 2, 285309 (1995)

50. Lindell, M.K., Whitney, D.J.: Accounting for Common Method Variance in Cross-Sectional Research Designs. Journal of Applied Psychology. 86, 114-121 (2001)

51. Tarafdar, M., Maier, C., Laumer, S., Weitzel, T.: Explaining the link between technostress and technology addiction for social networking sites: A study of distraction as a coping behavior. Information Systems Journal. 30, 96-124 (2019)

52. Maier, C., Laumer, S., Eckhardt, A.: Information technology as daily stressor: pinning down the causes of burnout. Journal of Business Economics. 85, 349-387 (2015)

53. Southwick, S.M., Bonanno, G.A., Masten, A.S., Panter-Brick, C., Yehuda, R.: Resilience definitions, theory, and challenges: interdisciplinary perspectives. European Journal of Psychotraumatology. 5, 25338 (2014)

54. Sun, Y., Wenping, Z., Wang, N., Shen, X.-L.: Dual Processes, Buffering/Coping Effects, and Reciprocal Dynamics: The Social Demands-Resources Model of SNS Discontinuance. In: Proceedings of the 40th International Conference on Information Systems. Munich (2019)

55. Reinartz, W., Krafft, M., Hoyer, W.D.: The Customer Relationship Management Process: Its Measurement and Impact on Performance. Journal of Marketing Research. 41, 293-305 (2004)

56. Sanchez-Lopez, A., De Raedt, R., van Put, J., Koster, E.H.: A novel process-based approach to improve resilience: Effects of computerized mouse-based (gaze) contingent attention training (MCAT) on reappraisal and rumination. Behaviour Research and Therapy. 118, $110-120(2019)$

57. Aboody, D., Siev, J., Doron, G.: Building resilience to body image triggers using brief cognitive training on a mobile application: A randomized controlled trial. Behaviour Research and Therapy. 134, 103723 (2020)

58. Tarafdar, M., Tu, Q., Ragu-Nathan, T.S., Ragu-Nathan, B.S.: Crossing to the Dark Side: Examining Antecedents and Consequences of Technostress. Communications of the ACM. 54, 113-120 (2011) 